\title{
Pengaruh Stratifikasi Sosial Terhadap Kesadaran Hukum Kajian Empirik pada Universitas X
}

\author{
Dhian Tyas Untari ${ }^{1, *}$, Desyana Berliana ${ }^{2}$, Iswiyati Kunti ${ }^{2}$, Fadilah ${ }^{2}$, Tiara Yuliana Wanti ${ }^{2}$, \\ Sri Mega Susanty Viadolorosa Ninu ${ }^{2}$, Mifta hul Zannah ${ }^{2}$ \\ ${ }^{1}$ Fakultas Ekonomi dan Bisnis; Universitas Bhayangkara Jakarta Raya; Jl Perjuangan 081, \\ Marga Mulya, Bekasi Utara, 02188955882/ +622188955871; e-mail: \\ dhian.tyas@dsn.ubharajaya.ac.id \\ 2 Fakultas Hukum; Universitas Jayabaya; JI Pulomas Selatan, Pulo Gadung, Jakarta Timur, \\ 0214700874; e-mail: desyanaberliana@gmail.com, iswiedogawa@gmail.com, \\ fadilahwasolo@gmail.com, wtiaray@gmail.com. Viadolorossa0208@gmail.com, \\ huljanahmifta7@gmail.com \\ * Korespondensi: e-mail: dhian.tyas@dsn.ubharajaya.ac.id \\ Submitted: 24/11/2021; Revised: 01/12/2021; Accepted: 08/12/2021; Published: 31/12/2021
}

\begin{abstract}
Social stratification and legal awareness are topics of study, especially in the social sciences, which are very interesting to do. The paradigm that the higher the education will increse the more of law awareness, becomes a phenomenon that needs to be discussed. This study aims to; 1) analyze whether there is an effect of educational stratification on legal awareness, 2) analyze how to build legal awareness in the community. The study involved 30 respondents who were academics from University X, Bekasi. Education Straktas are classified into three; S1, S2 and S3. Indicators related to legal awareness are legal knowledge, legal understanding, legal attitudes and legal behavior. Analysis using statistical parametric. The results of the study show that education strata do not have an effect on legal awareness.
\end{abstract}

Keywords: Legal awareness, Social science, Social stratification

\section{Abstrak}

Strakta sosial dan Kesadaran Hukum menjadi salah satu topik kajian khususnya pada IImu Sosial yang sangat menarik untuk di kaji secara lebih jauh. Paradikma bahwa semakin tinggi pendidikan maka akan semakin sadar aka hukum menjadi fenomena yang perlu untuk dibahas. Kajian ini bertujuan untuk; 1) menganalisis apakah terdapat pengaruh stratifikasi pendidikan terhadap kesadaran hukum, 2) menganalisis terkait bagaimana membangun kesadaran hukum pada masyarakat. Kajian melibatkan 30 responden yang merupakan sivitas akademik dari Universitas X, Bekasi. Strakta Pendidikan diklasifikasikan menjadi tiga; S1, S2 dan S3. Indikator terkait kesadaran hukum adalah pengetahun hukum, pemahaman hukum, sikap hukum dan prilaku hukum. Analisis menggunakan statistic parametrik. Hasil penelitan menunjukan bahwa strakta Pendidikan tidak memberikan pengaruh terhadap kesadran hukum.

Kata kunci: Kesadaran Hukum, IImu Sosial, Stratifikasi sosial

\section{Pendahuluan}

Manusia adalah makhluk sosial yang selalu membutuhkan interaksi dengan manusia lain secara sehat. Adanya interaksi sosial ini akan mempengaruhi pembentukan sebuah kelompok. Secara umum pengelompokan masyarakat Indonesia terbagi menjadi dua bentuk. Pertama, pengelompokan secara horizontal berupa deferensiasi dan Kedua, pengelompokan 
Dhian Tyas Untari, Desyana Berliana, Iswiyati Kunti, Fadilah, Tiara Yuliana Wanti, Sri Mega Susanty Viadolorosa Ninu, Mifta hul Zannah

secara vertikal berupa stratifikasi sosial (Maunah, 2015). Status tersebut diakibatkan oleh banyak faktor seperti karena keturunan, pendidikan, dan agama (Ali, 2015).

Setiap strakta dalam masyarakat memiliki fungsi dan peranan yang berbeda. Pada masyarakat yang relatif kompleks dan maju tingkat kehidupannya, maka sistem lapisan dalam masyrakatpun akan semakin kompleks itu. Keadaan ini disebabkan karena jumlah manusia yang semakin banyak, maka kedudukan (pembagian tugas kerja), hak-hak, kewajiban, serta tanggung jawab sosial menjadi semakin kompleks juga (Mariani, 2019).

Terkait posisi setiap manusia dalam hukum. Sesuai dengan yang tercantum pada pasal 27 ayat (1) UUD 1945 bahwa "semua warga negara bersamaan kedudukannya di dalam hukum". Makna equality before the law ditemukan di hampir semua konstitusi negara. Inilah norma yang melindungi hak asasi warga negara. Namun menegakkan equality before the law bukan tanpa hambatan. Bisa berupa hambatan yuridis dan politis, atau hambatan sosiologis dan psikologis (Triwulandari, 2020).

Berbicara tentang apa itu hukum, tidak berhenti hanya pada definisi hukum yang kemudian memunculkan teori-teori hukum. Secara lebih mendalam, dalam usaha penegakan hukum dalam mengatur dan menjaga kestabilitasan kehidupan dalam masyarakat, konsep kesadaran terhadap hukum itu sendiri menjadi sangat penting untuk dikaji secara lebih jauh (Maria, 2001). Kesadaran yang baik terhadap hukum yang hidup dalam masyarakat merupakan suatu keutamaan (Subiharta, 2015).

Paradikma bahwa semakin tinggi pendidikan maka akan semakin sadar aka hukum menjadi fenomena yang perlu untuk dibahas. Kajian ini bertujuan untuk; 1) menganalisis apakah terdapat pengaruh stratifikasi pendidikan terhadap kesadaran hukum, 2) menganalisis terkait bagaimana membangun kesadaran hukum pada masyarakat.Berdasarkan latar belakang tersebut, maka prnting untuk mengkaji lebih jauh tentang pengaruh stratifikasi sosial masyarakat terhadap kesadaran hukum.

Istilah stratifikasi (stratification) berasal dari kata strata dan stratum yang berarti lapisan. Karena itu stratifikasi sosial (social stratification) sering diterjemahkan dengan pelapisan masyarakat. Sejumlah individu yang mempunyai kedudukan (status) yang sama menurut ukuran masyarakatnya, dikatakan berada dalam suatu lapisan (stratum). Stratifikasi sosial adalah sistem pembedaan individu atau kelompok dalam masyarakat, yang menempatkannya pada kelas-kelas sosial yang berbeda-beda secara hierarki dan memberikan hak serta kewajiban yang berbeda-beda pula antara individu pada suatu lapisan dengan lapisan lainnya.

Abdul Aziz (dalam Maunah, 2015) menyebutkan salah satu bentuk startifikasi sosia adalah berdasarkan kriteria ilmu pengetahuan atau pendidikan. Kriteria atas dasar pendidikan terdapat strata sosial yaitu: 1) golongan yang berpendidikan tinggi, 2) golongan yang berpendidikan menengah, 3) golongan yang berpendidikan rendah.

Kesadaran hukum merupakan kesadaran atau nilai-nilai yang terdapat dalam manusia tentang hukum yang ada atau tentang hukum yang diharapkan ada. Dengan demikian yang ditekankan dalam hal ini adalah nilai-nilai tentang fungsi hukum dan bukan terhadap kejadian- 
kejadian yang konkret dalam masyarakat yang bersangkutan. Bila demikian, kesadaran hukum menekankan tentang nilai-nilai masyarakat tentang fungsi apa yang hendaknya dijalankan oleh hukum dalam masyarakat (Usman, 2014). Indikator-indikator dari kesadaran hukum antara lain a) Indikator pertama adalah pengetahuan hukum Seseorang mengetahui bahwa perilakuperilaku tertentu itu telah diatur oleh hukum. Peraturan hukum yang dimaksud disini adalah hukum tertulis maupun hukum yang tidak tertulis. Perilaku tersebut menyangkut perilaku yang dilarang oleh hukum maupun perilaku yang diperbolehkan oleh hukum. b) Indikator kedua adalah pemahaman hukum Seseorang warga masyarakat mempunyai pengetahuan dan pemahaman mengenai aturan-aturan tertentu, misalnya adanya pengetahuan dan pemahaman yang benar dari masyarakat tentang hakikat dan arti pentingnya UU No. 1 Tahun 1974 tentang perkawinan. c) Indikator yang ketiga adalah sikap hukum Seseorang mempunyai kecenderungan untuk mengadakan penilaian tertentu terhadap hukum. d) Indikator yang keempat adalah perilaku hukum, yaitu dimana seseorang atau dalam suatu masyarakat warganya mematuhi peraturan yang berlaku.

Berdasarkan pengertian tersebut, maka kerangka pemikiran terlihat pada gambar 1 dan hipotesis yang akan dibangun adalah sebagai berikut,

$\mathrm{Ho}=$ Strakta Pendidikan tidak memberikan pengaruh terhadap kesadaran hukum

$\mathrm{Ha}=$ Strakta Pendidikan memberikan pengaruh terhadap kesadaran hukum

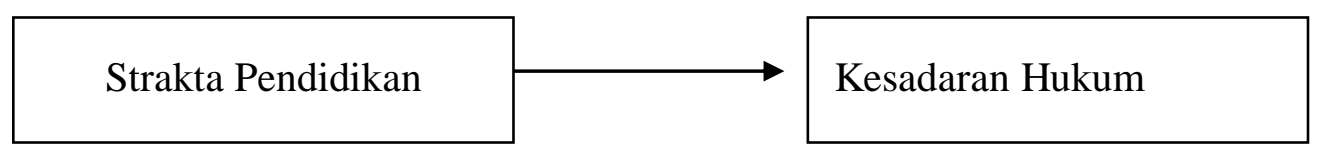

Sumber: Hasil Penelitian (2021)

Gambar 1. Kerangka pemikiran

\section{Metode Penelitian}

Penelitian melibatkan sivitas akademik pada Universitas $X$ yang berlokais di Bekasi, Jawa Barat. Stratifikasi sosial yang menjadi objek dalam penelitian adalah strakta pendidikan. Maka dalam penelitian mengklasifikasikan responden berdasarkan klasifikasi Sarjana, Magister dan Doktor. Distribusi jumlah sample adalah sebagai berikut pada tabel1 berikut

Tabel 1. Distribusi responden

\begin{tabular}{ccc}
\hline No & Pendidikan & Jumlah \\
\hline 1 & S1 & 12 \\
\hline 2 & S2 & 13 \\
\hline 3 & S3 & 8 \\
\hline \multicolumn{3}{r}{ Total responden } \\
\hline
\end{tabular}

Sumber: Hasil Pengolahan Data (2021)

Pada langkah awal penelitian, dilakukan uji validitas dan uji reliabilitas, untuk mengetahui kevalidan dan kekonsistenan instrumen penelitian saat digunakan dilapangan. Setelah itu dilakukan analisis lanjutan yang terdiri dari uji normalitas dan Anova. Uji normalitas 
Dhian Tyas Untari, Desyana Berliana, Iswiyati Kunti, Fadilah, Tiara Yuliana Wanti, Sri Mega Susanty Viadolorosa Ninu, Mifta hul Zannah

(Kolmogorov-Smirnov) diperlukan untuk mengetahui model statistik yang digunakan. Anova digunakan untuk menguji hipotesis dengan tiga rata-rata sampel independent.

\section{Hasil dan Pembahasan}

Pada langkah pertama dilakukan uji validitas dan reliabilitas instrumen penelitian. Hal ini dilakukan untuk mengetahui apakah instrumen yang akan dilakukan dalam penelitian benar merepresentasikan apa yang akan diteliti dan untuk mengetahui keandalan instrumen penelitian jika digunakan secara berulang. Maka dengan melakukan perbandingan antara $r$ hitung dan $r$ tabel dimana nilai $r$ tabel diperoleh dari $r$ hasil kali tabel momen dengan taraf signifikansi $5 \%$ dengan $n=280$, maka nilai $r$ table adalah 0,3061. Maka jika $r$ hitung $>0,3061$, maka butir pertanyaan angket tersebut valid. Hasil $r$ hitung dari masing-masing pertanyaan terlihat pada table 2 berikut

Tabel 2. Variable Validity

\begin{tabular}{cccc}
\hline Attribute & R Count & R Table & Description \\
\hline I1.1 & 0,450 & 0,3061 & Valid \\
\hline I1.2 & 0,551 & 0,3061 & Valid \\
\hline I1.3 & 0,622 & 0,3061 & Valid \\
\hline I1.4 & 0,421 & 0,3061 & Valid \\
\hline I2.1 & 0,521 & 0,3061 & Valid \\
\hline I2.2 & 0,459 & 0,3061 & Valid \\
\hline I3.1 & 0,581 & 0,3061 & Valid \\
\hline I3.2 & 0,641 & 0,3061 & Valid \\
\hline I3.3 & 0,531 & 0,3061 & Valid \\
\hline I4.2 & 0,501 & 0,3061 & Valid \\
\hline
\end{tabular}

Sumber: Hasil Pengolahan Data (2021)

Uji reliabilitas menggunakan koefisien Alpha Cronbach. Berdasarkan nilai yang diperoleh dari masing-masing atribut pelayanan memiliki nilai Cronbach Alpha diatas 0,5 (Table 2), maka setiap butir pertanyaan reliable dan dapat digunakan dalam proses penelitian selanjutnya.

Tabel 3. Variable Reliability

\begin{tabular}{lcl}
\multicolumn{1}{c}{ Attribute } & Cronbach's Alpha & Description \\
\hline Indikator 1 & 0,673 & Reliable \\
\hline Indikator 2 & 0,689 & Reliable \\
\hline Indikator 3 & 0,591 & Reliable \\
\hline Indikator 4 & 0,702 & Reliable
\end{tabular}

Sumber: Hasil Pengolahan Data (2021)

Hasil penelitian pada uji normalitas Kolmogorov-Smirnov menunjukan nilai sig. adalah 0.200 (lebih besar dari nila alpha $=0,05$ ), dengan demikian menunjukkan bahwa data berdistribusi normal. Dengan demikian maka penelitian dilanjutkan dengan metode statistic non 
marametrik. Berdasarkan uji Anova (untuk menguji hipotesis) dengan Df between $=3$ dan Df within $=26$, didaptkan nilai $F$ table 3,47 . Pada hasil rekapitulasi dan perhitungan Anova dihasilkan nilai $F$ hitung adalah 2,95. Dengan demikian mengartikan bahwa Ho diterima yang artinya tidak terdapat perbedaan kesadaran hukum antara orang yang berpendidikan S3, S2 maupun S1.

Stratifikasi sosial terbentuk dan berkembang dalam masyarakat yang kemudian memberikan pembeda antara manusia satu dengan lainnya, serta golongan satu dengan lainnya (Zainuddin, 2006). Pendidikan merupakan salah satu kreteria pada masyarakat dalam menentukan dimana posisi dalam strakta tersebut. Terkait dengan kesadaran hukum, pemahaman terhadap ilmu dan pendidikan yang semakin tinggi tidak mempengaruhi kesadaran seseorang terhadap hukum yang berlaku di masyarakat. Hal ini sejalan dengan penelitian yang dilakukan Widarukmi (2020) bahwa tingkat pendidikan bukanlah faktor utama dalam mempengaruhi kesadaran hukum masyarakat.

Banyak faktor yang mempengaruhi kesadaran seseorang terhadap hukum, diantarnya adalah penanaman nilai-nilai keluarga, suku, dan lingkungan yang kemudian membentuk sebuah kepribadian. Kepribadian ini yang kemudian menentukan kesadaran seseorang untuk mentaati atau tidak mentaati hukum. Sedangkan menut Mariani (2019), masalah kepatuhan hukum merupakan proses psikologis yang dapat ditinjau dari 3 (tiga) proses dasar yaitu compliance yang diartikan sebagai suatu kepatuhan yang didasarkan pada harapan akan suatu imbalan dan usaha untuk menghindarkan diri dari hukuman yang mungkin dijatuhkan, identification yang terjadi bila kepatuhan terhadap kaidah hukum ada bukan karena nilai intrinsiknya, akan tetapi agar keanggaotaan kelompok tetap terjaga serta ada hubungan baik dengan mereka yang diberi wewenang untuk menerapkan kaidah-kaidah hukum tersebut, dan internalization dimana seseorang mematuhi kaidah-kaidah hukum dikarekan secara intrinsik kepatuhan tadi mempunyai imbalan.

Terkait dengan bagaimana membangun kesadaran hukum, Sudikno Mertokusumo (dalam Kenedi, 2015) berpendapat bahwa peningkatan kesadaran hukum masyarakat pada dasarnya dapat dilakukan melalui dua cara, yaitu dalam bentuk tindakan dan pendidikan. Penyadaran hukum masyarakat yang dilakukan dalam bentuk tindakan adalah dengan memperberat ancaman hukuman atau dengan lebih memperketat pengawasan ketaatan warga negara terhadap undang-undang dan melatih para penegak hukum agar dapat memberikan keteladanan kepada masyarakat dalam rangka untuk meningkatkan kesadaran hukum masyarakat. Disisi lain, adanya korelat antara bidang pendidikan dengan hukum untuk melahirkan seorang individu yang benar-benar taat azas (Rifqi, 2017). Dengan demikian pendidikan memiliki peranan yang penting dalam membangun budaya sadar hukum pada generasi muda. 
Dhian Tyas Untari, Desyana Berliana, Iswiyati Kunti, Fadilah, Tiara Yuliana Wanti, Sri Mega Susanty Viadolorosa Ninu, Mifta hul Zannah

\section{Kesimpulan}

Pendidikan salah satu kriteria penentu strakta seseorang pada lingkungannya, tetapi pada penelitian menunjukan bahwa strakta Pendidikan tidak memberikan dampak pada kesadaran hukum. Banyak faktor yang mempengaruhi kesadaran seseorang terhadap hukum, diantarnya adalah penanaman nilai-nilai keluarga, suku, dan lingkungan. Usaha dalam meningkatkan kesadaran hukum secara umum dadapt dilakukan dalam 2 bentuk yaitu bentuk tindakan dan Pendidikan, artinya membangun kesadaran hukum tidak akan bisa lepas dari aturan yang kemudian mengikat masyarakat untuk berlaku dan bertindak sesuai dengan aturan yang sudah ditetepkan, selain itu untuk menjaga dan membangun kesadaran hukum yang lebih masif perlu dibangun sebuah sistem pendidikan yang sarat dengan nilai, norma dan etika sehingga dapat membangun kesadaran hukum pada generasi muda.

\section{Daftar Pustaka}

Ali, R. H. S. A. (2015). Stratifikasi Sosial dan Kesadaran Kelas. Jurnal Sosial Dan Budaya Syar'i, 2(1), 32-48.

Kenedi, J. (2015). Studi Analisis Terhadap Nilai-Nilai Kesadaran Hukum dalam Pendidikan Kewarganegaraan (Civic Education) di Perguruan Tinggi Islam. 19(2), 205-216.

Maria. (2001). Pemahaman Tentang Hukum dan Kesadaran Hukum Masyarakat. Era Hukum, 1(9), 17-33.

Mariani. (2019). Kesadaran Hukum Peserta Didik dalam Berlalu Lintas. Phinisi Integration Review, 2(2), 281-289.

Maunah, B. (2015). Stratifikasi Sosial dan Perjuangan Kelas Dalam Perspektif Sosiologi Pendidikan. Ta'allum, 3(1), 19-39.

Rifqi, M. (2017). Tingkat Kesadaran Hukum Mahasiswa Terhadap Qanun no 6 tahun 2014 Tentang Hukum Jinayat (Studi Kasus Mahasiswa Fakultas Syariah dan Hukum UIN ArRaniry). Legitimasi, 6(1), 62-88.

Subiharta. (2015). Moralitas Hukum Dalam Hukum Praksis Sebagai Suatu Keutamaan. Jurnal Hukum Dan Peradilan, 4(3), 385-398.

Triwulandari, N. G. A. A. M. (2020). Problematika Pemberian Bantuan Hukum Struktural dan Non Struktural Kaitannya dengan Asas Equality Before The Law. Jurnal Ilmiah Kebijakan Hukum, 14(3), 539-552.

Usman, A. H. (2014). Kesadaran Hukum Masyarakat dan Pemerintah Sebagai Faktor Tegaknya Negara Hukum di Indonesia. Jurnal Wawasan Hukum, 30(1), 26-54.

Widarukmi, H. A. (2020). Pengaruh Tingkat Pendidikan Terhadap Kesadaran Hukum Masyarakat Sangkrah, Kecamatan Pasar Kliwon, Kota Surakarta. UNS.

Zainuddin, A. (2006). Sosiologi Hukum. Jakarta: Sinar Grafika. 